\title{
Sport and the Political Economy: Considerations for Enhancing the Human Condition
}

\author{
By Ian Culpan* \\ Caroline Meier ${ }^{\dagger}$
}

\begin{abstract}
This paper highlights how sport, at the elite level, has been commodified by global market forces. These forces have brought about a deep-seated and profound upheaval of previous economic, social, political and cultural arrangements, and behaviours toward sport, resulting in the moral and ethical base of sport being challenged as a 'past practice' reminiscent and a relic of the modern age. However, some scholars are concerned about the present global influence and are suggestive of ways in which such commodified changes can be regulated to protect sport's social, educative and moral underpinnings. The paper targets suggestions for regulation of the political economy of sport and anchors those by drawing on education, particularly the philosophy of Olympism within physical education. In making those suggestions reinforcement is given for the need for sport, at whatever level, to uphold its value in enhancing the human condition.
\end{abstract}

Keywords: Political economy, sport and physical education, Olympism, commodification of sport

\section{Introduction}

Sport in the 21 st century has become a highly contested and paradoxical venture. Advocates of sport claim that it brings people and communities together and has significant educative, moral and social value (United Nations Educational, Scientific and Cultural Organisation (UNESCO), 2013). Others, somewhat more sceptical, claim that it is a source of division, a creator of conflict, a tool of the privileged corporate sector, and the perpetrator of inequalities and injustices (Miller, 2009). It is exploited by diverse political systems in order to achieve governmental objectives. While these dichotomies exist and continue to shape, modify and change sport, the whole social construct of sport has entered a period of rapid transformation influenced by economic, technological, cultural and political factors. Sport is under-going dramatic transformation from

"diversion to consumption, to spectacle to beyond, where sports events and teams have become vehicles to promote strategies of growth, investment,

*Professor and Director of New Zealand Centre for Olympic Studies, University of Canterbury, New Zealand.

${ }^{\dagger}$ Olympic Studies Centre, German Sport University of Cologne, Germany. 
capital accumulation, ... national political success and sites for the solidification and regeneration of national or regional identity" (Nauright, 2005, p. 209).

While diverse political systems make use of sport as a means to achieve national political objectives, sport has become a globalised industry where priority is given to economic imperatives and dominant forms of culture. From an economic perspective the neo-liberal free market ethos emphasising the flow of free trade has resulted in the commodification of sport and indeed the athlete. Here goods and services (events, athletes, merchandise, and media) are contracted and traded on a global basis (Nauright, 2005). From a cultural perspective, globalisation ("the multi directional flow and processes of capital, market products and images between cultures", (Silk \& Jackson, 2000, p.102)) has seen cultural practices of sport, generally belonging to the West or imperial powers, gaining dominance and given privilege e.g. privileging Western forms of sport, and the adoption of American style commercially orientated media coverage of sport broadcasting on a global basis (Thibault, 2009).

In this paper, the impact of the globalisation on sport and in this respect the phenomenon of commodification of sport and its implications for sport are analysed and discussed by reviewing the according literature. Educational approaches are suggested to address the commodification and in the following section, the educational value of sport and physical education are reviewed. Thereupon, the philosophy of Olympism is introduced and, on this basis, Olympism education is proposed as a necessary critically educative tool, capable to affect the political economy of sport and thus to address the negative implications of globalisation on sport.

\section{Commodification of Sport}

The phenomenon of commodification of sport has received much attention in the academic literature (Collins \& Jackson, 2007; Slack, 2004; Walsh \& Giulianotti, 2007). As Walsh and Giulianotti (2007) point out it has brought about a deep-seated and profound upheaval of previous economic, social, political and cultural arrangements, and behaviours toward sport. They argue that the commodification of sport is complex and while popular opinion may indicate that such changes in behaviour and arrangements, particularly toward money and corresponding markets, have detrimental effects to the philosophy and practice of sport, they make some important points. Firstly, commodification of sport is centred at the elite level; secondly, there have been substantial benefits accrued from this practice, particularly for athletes and spectators e.g. quality of events, quality of stadia and access to media coverage. However, in their third point Walsh and Giulianotti acknowledge that the commodification of sport gives rise to 'moral grounds of concern'. Here they identify those instances where commodification has disagreeable moral and ethical consequences. They label these disagreeable consequences 'pathologies' 
which "involve the violation of what we might take to be fundamental moral values that emerge from or through sporting activity be it at the elite or grassroots level" (ibid., p.10). Walsh and Giulianotti's four pathologies that generate disagreeable consequences are:

1. The Motivational Pathology: the commodification of sport is pathological when it erodes the attitudes of those who participate in sport so that they no longer pursue sport as a goal in itself.

2. The Instrumentalist Pathology: the commodification of sport is pathological when it leads others to regard athletes and sport itself as mere means and not an ends-in-themselves.

3. The Distributive Pathology: the commodification of sport is pathological when it gives rise to forms of distributive injustice.

4. The Pragmatic Pathology: the commodification of sport is pathological when it undermines the long term profitability of any sporting activity (ibid., p.120).

In highlighting their 'pathological concerns' in the commodification of sport Giulianotti and Walsh provide useful suggestions in how these might be prevented. They endorse a mixed market economy where free enterprise is moderated and regulated by the State and global sporting organisations. While it is not the purpose of this paper to explore all their suggestions in detail it is pertinent to record them. Their suggestions involve: the State regulating markets by 'blocking' detrimental practices, preventing and restricting unjust, excessive and corrupting behaviours leading to the identified pathologies; reinvestment into 'grassroots sport via the State and global sporting bodies (a moral obligation given that today's elite athletes progressed from the 'grass roots'); moral exhortation through education about the underlying virtues, ideals and behaviour inherent in sport; and an expectation of the individual and/or collective to resist immoral behaviours and practices and take individual subsequent social action. In essence, what Walsh and Giulianotti are suggesting is to diminish the "influence of money in sport, and reawakening in its practitioners a love for goals other than money" (ibid., p.131).

What is of particular relevance in Walsh and Giulianotti's analysis to this paper's purpose is the suggestion of a grassroots and education focus. Their proposal is to purpose the continued importance of sport in seeking human excellences while their work hints that sport, through the political economy, with State intervention and education, still has an important part to play in enhancing the human condition. It is to this we now wish to turn with a particular emphasis on education, physical education and sport education in the school context. 


\section{Physical Education and Sport Education}

Some time ago now, Arnold (1997) argued that sport was a valued human practice and could make useful and significant contributions to the enrichment of the human experience. Arnold further suggested that sport could help construct a meaningful pattern to life and assist individuals and groups to become more fully human. In his analysis he offered that sport was only a valued practice when it was characterised by: rules and regulations, specific traditions and goals, high levels of physical skill, competition, rivalry and contest, social interaction and physical exertion. While these characteristics are commonly accepted, Arnold offered a characteristic most often missing from other attempts at conceptualising sport. He believed that sport needed to be practised in a moral and ethical sense. His thesis was that such moral and ethical practises involved duty, obligation, fairness, courage, honesty and justice - which are essentially the foundational ideals of sport and which contribute to sport's social and educative value. To Arnold "sport in the context of the school, no matter what other purposes it may also serve, is or should be a form of moral education" (p.xiii). Walsh and Giulianotti (2007) seemingly agreed with Arnold by identifying the important 'moral exhortation' as one solution to their 'pathologies'. Other scholars, however, have intimated that more contemporary developments in physical education and sport in schools have been influenced by the vital role it plays in the maintenance and continuance of advanced forms of Western capitalism (Evans, 2012) and had little to do with moral and ethical advancement. Miller (2009) for example argued that the elevation of sport "as a transcendent form of life, beyond the social or embodying its best aspects is ridiculous" (p.190). This is in line with Foucault's argumentation (1980) who argued that capitalism recognised the importance of physical education and body control while it neglected its moral and ethical value. He argued physical education and sport were used to educate docile bodies for control, discipline and regulation in preparation for a work force in order to supply the labour markets.

As Cameron (1993) argued, such interrelationships - and the lack of acknowledgement for moral and ethical education through sport - can be summarised in the following way:

The very nature of physical education and sport reveals the relations of power being played out in the body (...) in keeping with a capitalist mode of production, sport bodies are disciplined through work: 'work out', 'speed work' etc. (...). The body is thus subordinate to the purpose of physical education and sport. On the other hand, physical education and sport builds healthy bodies, it is also used to foster control over the mind (p.177) (Authors emphasis).

It is interesting to note that according to Foucault (1980), the development of capitalism is mirrored in the changing role of sport and physical education, 
where the focus is primarily on functional aspects such as body control and fitness while moral and ethical values are ignored. He argued that:

The manner in which capitalism has refined itself has a parallel in how the body has been refined, especially in terms of how it is internally and externally controlled and disciplined. In the initial stages of capitalism body control took the form of mass military style exercise, but as capitalism has evolved into a corporate form, so too has physical education and sport, with an emphasis moving from external control of the body (and person) to individual accountability for health and fitness development (cited Culpan, 2004, p. 227).

By stressing the change from external to internal control over the body, control is expected to result in self-regulation, self-actualisation and selfmaximisation (Evans, 2012). Foucault implicitly acknowledges that sport does not only contribute to capitalism but that it also benefits from it.

Still, as many scholars like Cameron (1993), Foucault (1980) Hargreaves (1996) and Kirk $(2010,1997)$ have argued, the role that physical education and sport have played in controlling and disciplining the body has ensured that it has survived in contemporary schooling simply because of the perceived benefits initially contributing to capitalism and now more particularly to the free market version of capitalism. These two analyses: Arnold's educative, social and moral function of sport in schools and Foucault's instrumental view of educating docile bodies for market purposes highlight a pathology identified by Walsh and Giulianotti (2007). In particular we refer to

The Instrumentalist Pathology: the commodification of (physical education)/sport are pathological when it leads others to regard (learners)/athletes and (physical education)/sport itself as mere means and not ends-in-themselves (ibid., p.120), (Author's emphasis)

which, according to Walsh and Giulianotti, could be addressed by providing moral exhortation through education. This is consistent with Arnold's (1997) argument that physical education and sport in schools should be for moral education. For Arnold, the educative and social value of physical education and sport has the potential to contribute to a 'flourishing life'. He claims that "physical education and sport can help constitute a meaningful pattern of life in which individuals can both find and extend themselves and provide the means by which individuals become persons" (Fraleigh, cited in Arnold, 1997, p.ix). This position draws on Foucault's technology of the self (Foucault, Martin, Gutman \& Hutton, 1988) which allows individuals, with the help of others, to transform themselves for the 'better'. Central in this transformation process are self-regulation, self-actualisation and more individual responsibility which arguably induce economic growth and prosperity (Evans, 2012). Despite this potential it is important to note that in Foucault et al.'s (1988) analysis of physical education and sport, sadly, the technologies of production and power 
also allow for physical education and sport to be used as an instrument for the coercion, manipulation and commodification of the body, for maximising economic imperatives beyond the self. However, by synthesising Arnold's (1997) and Walsh and Giulianotti's (2007) positions, physical education and sport education in schools potentially have a key role in moderating the rampant commodification of the sportive process. The way forward for this, we suggest, is to capture the power and potential of the philosophy of Olympism to utilise 'Olympism education' (note not Olympic education) within a physical education and sport education schooling context.

\section{Olympism and Olympism Education}

The philosophy of Olympism, originally developed by Pierre de Coubertin (Müller, 2000), was "the religion of energy, the cultivation of intense will developed through the practice of manly sports, based on proper hygiene and public spiritedness, surrounded with art and thought" (cited in Müller, 2000, p. 44). In this development he sought to incorporate the concept of sport into the routine of school life and thereby capture its educative and social potential. More specifically de Coubertin could see that the moral strength of young people (males) could be developed through systematic experiences of sport. The development of these ideas was significantly influenced by the British Public School system where codified games were a legitimate part of character development for the young male (Culpan \& Wigmore, 2010). The British called this muscular Christianity and de Coubertin developed these ideas further through the idea of religio-athletae, which was - besides his ideas of 'rhythm and peace', 'aristocracy and achievement' and 'arts and culture' - one of the four pillars of Olympism. De Coubertin's relio-athletae had little to do with theology, and little to do with tin idols and gods. He argued that in the same way as the athlete in antiquity 'honoured the gods' by chiselling his body with exercise, modern sport could be considered as a religion in the widest sense because the modern athlete dedicates his performance to his country and thus to the modern society. His idea was based on the belief that sport and the athlete can contribute to the development of two pillars of modern society, democracy and internationalism (Müller, 2000) because, in competition, the athlete has to learn self-discipline, respect for rules, avoidance of cheating and respect towards fellow competitors. He argued that the modern athlete had to demonstrate noble and virtuous character traits and serve as a positive role model for society.

A critical consideration of contemporary elite sport reveals a gap between the ideal and reality which is why, despite its promising moral and ethical principles, Olympism is not without its critics. It is not the scope of this paper to provide a thorough critique of the concept of Olympism but it is prudent to provide brief comment and signal that it is a highly contested, contemporary concept. Knowledge of the criticisms of the Olympism concept, we argue, is necessary in order to be mindful of understanding its limits, and being able to 
apply it for the 'good'. Due to its universality and its early origins it is necessary to shape and reshape Olympism in order to contextualise it for schools and other environments. The dissemination of its main principles and thus the capitalisation of its benefits depends on acknowledging and avoiding its shortcomings. Furthermore, criticisms of Olympism provide a nurturing ground for the construction of Olympism education to evolve and develop as an alternative and more elaborate concept to present understandings particularly of present Olympic education programmes. Generally, criticisms of Olympism focus on its association with the Olympic Games, the Olympic Movement, its claims of universality and the datum that there is no immutable definition (Bale \& Christensen, 2004). Given that the mandate of the Games is to celebrate the concept of Olympism, much like Christmas is the celebration of the birth of Christ, scholars argue that the Games (like Christmas) have become so far removed from the ideals of Olympism (ideals of Christianity) that it is a pretence that needs to be rectified (ibid., 2004). Similarly one of the major tenets of the International Olympic Committee (IOC) is to promote the concept of Olympism through sport worldwide. Here critics argue that the behaviours and practices of the IOC and the political economy of sport through the commodification of it are so far removed from this concept that such a mission now lacks authenticity (Lenskj, 2012; Wamsley, 2004). In terms of universalism, any construct or concept claiming to be universal needs to be inclusive of all nations, across a wide range of socio-cultural constructs and have contemporary relevance (Parry, 2006). While Parry (2006) and Da Costa (2006) acknowledge the criticisms of universality, they offer a solution by differentiating between a concept and conception. Parry (2006) posits that if all counties can agree to a common set of values this then becomes the thin veneer of a universal concept. He then puts forward the suggestion that this thin veneer of agreement can be interpreted and qualified according to cultural contexts and specific circumstance. This interpretation he labels the conception of the concept. The conception provides the on-going richness and usefulness of the Olympism philosophy and overcomes the criticism of the universality of Olympism.

In reference to Olympism having no indisputable definition (Bale \& Christensen, 2004) scholars such as Martinkova (2012), Parry (2006), Segrave (1988) and Teetzel (2012) have all offered different understandings of what Olympism involves and they all set different focal points. Martinkova (2012) and Teetzel (2012) stress the educational and social value of Olympism: Martinkova (2012) argues that today the concept of Olympism draws on the 'goods' (values) inherent in sport (i.e. striving for victory, personal betterment, perseverance, controlled aggression, rule adherence, self and focused discipline) and the 'humanistic ideals' (added values) (i.e. respect for others, non-discrimination, unity, friendship, international understanding, peace, generosity and tolerance). As she argues these values - both 'inherent' and 'added' - are inter-related and woven into the competitive sports experience in a complex manner. The complexity resides in coordinating and giving coherence to the desire for victory, holistic education, and the quest to being 
ethical and human. Teetzel (2012) in her analysis has identified three major common threads to the concept of Olympism. These are fairness, equality and ethical behaviour. Besides these scholars' understandings of Olympism, each putting emphasize on particular aspects, the working conceptualization of Olympism extracted from the Olympic Charter provides a general orientation and serves as basis for this paper to move on:

Olympism is a philosophy of life, exalting and combining in a balanced whole the qualities of body, will and mind. Blending sport with culture and education, Olympism seeks to create a way of life based on the joy of effort, the educational value of good example, social responsibility and respect for universal fundamental ethical principles (IOC, 2014, P.11).

In acknowledging the many variations and nuances existing with understandings of Olympism and the criticisms and the problematic practices of the Olympic Games and the IOC, we are never-the-less supportive of Parry's (2007) argument, that while some may see Olympism as a naïve and fond hope, "the philosophy of Olympism has been the most coherent systematization of the ethical and political values underlying the practice of sport so far to have emerged". Bennett and Culpan (2014) go even further than Parry (2007) and suggest that Olympism is also one of the most coherent educative explanations of the aims of sport to have emerged over the last 100 years. Having distanced ourselves from the association that Olympism has with the Games and IOC practices, we are arguing this separation of the Olympism philosophy provides a progressive and generally more acceptable pathway for it to be better utilised as an educative tool. By doing this, we are in agreement with Arnold (1997), Binder (2012), Kidd (1996), Parry (2007) and even de Coubertin (Müller, 2000), in suggesting the contextualisation and conception of Olympism is a rightful and legitimate part of the education process and this is what we now refer to as Olympism education. Here we agree with Culpan and Wigmore (2010) and Parry (2007) that Olympism education (Authors emphasis) is best maximised through physical education and sport education in schools. One could also argue that it becomes the focus of the coaching process and be central and pivotal to the coach as educator (see Bennett \& Culpan, 2014).

In progressing this thesis it is necessary to provide a clear and concise construction of what we are meaning by Olympism education. Here the work of the New Zealand Centre for Olympic Studies (NZCOS) becomes useful. The NZCOS has conceptualised Olympism education as "a culturally relevant experiential process of learning an integrated set of life principles through the practice of sport" (Culpan \& Moon, 2009, p.1). Contextualising Olympism education for a schooling environment, arguably physical education becomes the 'curriculum area' in which this conceptualisation could be developed. The conceptualisation seemingly addresses many of the criticisms of present Olympic education programmes (see Culpan \& Wigmore, 2010) by acknowledging the importance of the cultural context; addressing the 
importance of making programmes relevant to the learner and encouraging students' active engagement by learning attitudes, values and behaviours through practising sport and physical activity. What is of particular importance is the reference to an 'engaged pedagogy'. This addresses, what we consider to be a very strong criticism that present Olympic type programmes tend to have no discernible pedagogy ${ }^{1}$. Of equal importance in this suggestion is it places the learner and Olympism at the core of learning and the ideological inscription' (see Lenksyj, 2012) of the IOC, and its practices, to the margins. Thus the Olympic Movement's interpretation of Olympic education is either reconceptualised or at the very least pushed to the periphery. This arrangement better addresses the short comings of Olympism as well as Lenskyj's (2012) and Kohe's (2010) criticisms of dominant manifestations of present Olympic education programmes as they claim that essentially present Olympic education programmes are a promotion of the IOC's own interest. Our proposition goes someway to address the suggestion by Arnold (1997) and Walsh and Giulianotti (2007) for the need for moral education around physical education and sport. Taking Culpan and Moon's (2009) concept and our argument here, Olympism education embedded in physical education can: be aligned with national physical education curricula; have active engagement in sport and physical activity; have less focus on the Olympic Games, create more focus on a contextual understanding of Olympism; and provide opportunities to develop a criticality ${ }^{2}$ around Olympism. Furthermore, it provides the possibility of playing an important educative and social role in helping to regulate the rampant commodification of sport that is presently going unchecked. It can achieve this by overtly adopting Walsh and Giulianotti's (2007) suggestion of specifically and formally addressing the pathologies present in contemporary sport by moral exhortation through education. Olympism education can address the underlying virtues, ideals and behaviour inherent in sport; and highlight an expectation of the individual and/or collective to resist immoral behaviours and practices and take necessary social action to address these. In advocating for such, we are mindful that in a globalised economy, where sport is commodified, there can be no nostalgia. There can be no going back to a 'de Coubertin fundamental approach' in the hope of addressing the pathologies identified earlier. We are not sponsoring such, but rather suggest a significant contemporary re-orientation for Olympic education to morph to Olympism education in order to become a necessary critically educative tool in addressing particular disagreeable consequences associated with the excessive commodification of sport.

\footnotetext{
${ }^{1}$ For a full analysis of a possible pedagogical approach to Olympism education see Culpan and Wigmore (2010) and Culpan and McBain (2012).

${ }^{2}$ Refer Culpan and Wigmore (2010), Lenksyj (2012) and Kohe (2010).
} 


\section{Final Comment}

In conclusion, there is a need for assistance in the regulation of the political economy of sport in order to make use of the potential of sport to contribute to maximizing the human condition. The commodification and commercialization of sport are likely to increase in the future, stretching to include other forms and other codes of sport. Having in mind its positive effects on and in sport, commercialization is not a problem per se. However, there is a need for action to be taken in order to ensure that the underlying idea of the educative, social and moral ethos of sport can be upheld. The exigency for market regulation, and in this sense a systematic and elaborate moral education via sport, becomes even more evident when taking into consideration that sport is also threatened to be exploited for coercion and manipulation.

Based on, and incorporating the criticisms of Olympism and Olympic Education programmes of the IOC, the concept of Olympism education, particularly aligned with school physical education, can make significant contributions and progress. This progress of a 'new imagery' needs to be bifocal. Those of confronting social injustices and inequalities at the personal level and thereby empowering the individual but also working and contributing to altering structural arrangements that can moderate the political economy of sport itself. While advocating this particular alignment, we are mindful that introducing criticality to the pedagogical process of Olympism education does not inherently mean that 'one size fits all' across the globe. A contribution of Olympism education to the modification and regulation of the political economy of sport and its corresponding commodification requires an underlying conception that acknowledges the importance of diverse and relevant contextualizations. This progress can be achieved by ensuring that such education programmes result in the emergence of a global populace who understand the key principles of sport and physical education: that, by being active, virtuous and critical consumers of sport at whatever level, the human condition can be enhanced.

\section{References}

Arnold, P. (1997). Sports Ethics and Education. London: Cassell.

Bale, J. \& Christensen, M. (2004). Post-Olympism? Questioning sport in the twentyfirst century. New York: Berg Publishers.

Bennett, B., \& Culpan, I. (2014). The coach as educator: Content and pedagogical frameworks. Journal of Physical Education \& Health: Social perspective, 3(5): 5-18. Retrieved from http://jpe-health.pwsz.raciborz.edu.pl.

Binder, D. (2012). Olympic values education: Evolution of a pedagogy. Educational Review, 64(3), 276-302.

Cameron, J. (1993). The sociology of sport. In H. Perkins and G. Cushman (Eds.), Leisure, recreation and tourism. Auckland: Longman Paul.

Collins, C., \& Jackson, S. (Eds.) (2007). Sport in Aotearoa/New Zealand society (2 ${ }^{\text {nd }}$ ed.). Palmerston North: Dunmore Press. 
Culpan, I. (2004). Physical education curriculum: A humanistic positioning. In A. O'Neill, J. Clark, and R. Openshaw, Reshaping culture, knowledge and learning (pp. 225-243). Palmerston North; Dunmore Press.

Culpan, I., \& McBain, S. (2012). Constructivist pedagogies for Olympism education. Asia-Pacific Journal of Health, Sport and Physical Education, 3(2), 95-108.

Culpan, I., \& Moon, C. (2009). Olympism education. Unpublished work. New Zealand Centre for Olympic Studies, University of Canterbury, Christchurch, NZ.

Culpan, I., \& Wigmore, S. (2010). The Delivery of Olympism Education within a Physical Education Context Drawing on Critical Pedagogy. International Journal of Sport and Health Science, 8, 67-76. http://dx.doi.org/10.5432/ijshs.20090028.

Da Costa, L. (2006). A never ending story: The philosophical controversy over Olympism. Journal of the Philosophy of Sport, 33, 157-173.

Evans, J. (2012). Neoliberalism and the future for a socio-educative physical education. Physical Education and Sport Pedagogy, 19(5), 545-558.

Foucault, M. (1980). Body power In C. Gordon (Ed.), Power knowledge: Selected interviews and other writing 1972-197 pp.55-63. Brighton: Harvester Press.

Foucault, M., Martin, L., Gutman, H., \& Hutton, P. (1988). Technologies of the self: A seminar with Michel Foucault. USA: University of Massachusetts Press.

Fraleigh, W. (1997). Foreword. In P. Arnold, Sport, Ethics and Politics (pp. vi-ix). London: Cassell Education.

Hargreaves, J. (1996). The body sport and power. In J. Horne, D. Jary and A. Tomlinson (Eds.), Sport leisure and social relations. The Sociological Review, Monograph 33. Staffordshire: Sociological Review Office.

International Olympic Committee (IOC) (2014). Olympic Charter. Lausanne: IOC. Retrieved from http://www./document/olympic-charter_en.pd.

Kidd, B. (1996). Taking the rhetoric seriously: Proposals for Olympic education. Quest, 48, 82-82.

Kirk, D. (2010). Physical education futures. London: Routledge.

Kirk, D. (1997). Schooling bodies in new times: The reform of school physical education in high modernity. In J. M. Fernandez-Balboa (Ed.), Critical postmodernism in human movement, physical education, and sport (pp.39-65). New York: State University of New York Press.

Kohe, G. (2010). Disrupting the rhetoric of the rings: A critique of olympic idealism in physical education. Sport Education and Society, 15(4), 479-94.

Lenskyj, H. (2012). Olympic education and Olympism: Still colonizing children's minds. Educational Review, 64(3), 265-274.

MacAloon, J. J. (2016). Agenda 2020 and the Olympic Movement. Sport in Society, 119.

Martinkova, I. (2012). Teaching values in movement activities: Inherent and added values. ACTA Universitatis Carolinae Kinathropologica, 48(2), 111-119.

Miller, T. (2009). Michel Foucault and the critique of sport. In B. Carrington and I. MacDonald (Eds.), Marxism, cultural studies and sport (pp. 181-194). New York Routledge.

Müller, N. (2000). Olympism: Selected writings. Lausanne: International Olympic Committee.

Nauright, J. (2005). Conclusion: The political economy of sport in the twenty-first century. In J. Nauright and K. Schimmel, The political economy of sport (pp. 208-214). New York: Palgrave Macmillan. 
Parry, J. (2007). The religio-athletae, Olympism and peace. In J. Parry, S. Robinson, N. Watson \& M. Nesti (Eds.), Sport and spirituality: An introduction (pp. 201214). London: Routledge.

Parry, J. (2006). Sport and Olympism: Universals and multiculturalism. Journal of the Philosophy of Sport 33(2), 188-204.

Segrave, J. (1988). Towards a definition of Olympism. In J. Segrave \& D. Chu, (Eds.), The Olympic Games in transition (pp. 149-161). Champaign, Illinois: Human Kinetics

Silk, M., \& Jackson, S. (2000). Globalisation and sport in New Zealand. In C. Collins (Ed.), Sport in New Zealand Society (pp. 99-114). Palmerston North: Dunmore Press.

Slack,T. (2004). (Ed.). The commercialisation of sport. London: Routledge

Teetzel, S. (2012). Optimizing Olympic education: A comprehensive approach to understanding and teaching the philosophy of Olympism. Educational Review, 64(3), 317-332.

Thibault, L. (2009). Globalization of Sport: An Inconvenient Truth. Journal of Sport Management, 23, 1-20.

United Nations Educational, Scientific and Cultural Organisation (UNESCO) (2013). Berlin declaration. 5th International Conference of Ministers and Senior Government Officials Responsible for physical education and Sport (MINEPS V). Berlin: 28-30 May, 2013. Berlin, Germany: UNESCO.

Walsh, A., \& Giulianotti, R. (2007). Ethics, money and sport: This sporting mammon. London: Routledge.

Wamsley, K. (2004). Laying Olympism to rest. In J. Bale \& M. Christensen (Eds.), Post-Olympism: Questioning sport in the twenty-first century (pp. 231-240). New York: Berg Publishers. 